which is nearly four or five times more potent, and charas, the effects of which are even stronger than those produced by ganja, are mostly smoked. The cultivation of the hemp plant which grows wild in Northern India along the southern slopes of the Himalayas is strictly controlled for narcotic purposes. The total consumption of hemp drugs in British India during 1934-35 amounted to 1,031,496 lb.

According to the writers there are at least between 855,844 and $1,000,000$ hemp drug addicts in India, or approximately $0.5-1$ per cent of the total population. The main causes of addiction in order of frequency are association with other addicts, religious and emotional factors, substitution for other drugs, disease and minor ailments, and hard work, worry or strain. The commonest age to contract the habit is between twenty-one and thirty. The effects of the drug on the central nervous system can be divided into three stages : first, the stage of primary stimulation and excitement; secondly, the stage of depression and anæsthesia; and thirdly, the stage of secondary stimulation and excitement. Moderate habitual use may not be attended with harmful effects, but continued excessive indulgence impairs the normal functioning of the nervous system, renders the addict incapable of mental exertion and causes general debility and premature decay.

\section{Robert Boyle}

Axтноуян Robert Boyle (1627-1691) is well known for his law of compression of gases and for his clear definition of a chemical element (given in his "Sceptical Chymist", 1661), his many other services to chemistry and physics are less appreciated. M. Schofield (Chem. and Ind., 59, 615; 1940) has sketched some of these. Boyle's work in physics centred around his air pump, several models of which were constructed, and his experiments in a vacuum are of considerable interest, particularly in connexion with the barometer, the fact that sound is not propagated in a vacuum, and the boiling of water under reduced pressure. Experiments on freezing mixtures and hydrostatics, including the measurement of specific gravities, were also carried out by Boyle. In the field of chemistry he criticized the prevailing views on elements and pointed the way to a correct view of these, made experiments on combustion which emphasized the importance of the air, investigated the action of acids and alkalis on indicators, prepared phosphorus and ether, and was near the correct interpretation of respiration.

\section{Dr. Désire Bourneville}

Dr. Désirḱ Maglotre Bournevinle, a pioneer in the welfare of defective children, was born at Garencières in Normandy on October 21, 1840. He studied medicine in Paris, where he qualified in 1870. Three years later he founded Le Progrès Médical, which soon became one of the leading French medical journals. In 1879 he was appointed senior physician to the Bicêtre infirmary, where he took charge of a service almost entirely devoted to idiocy and other forms of mental defect in children and published the
Comptes revitus de Bicetre. In the following year he founded the Archives de Neurologie under the patronage of Charcot, whose works he had edited some years previously. Bourneville was one of the first in France to confirm Hertoghe's observations on thyroid cachexia and to prove the value of thyroid medication. He was also the first to describe the association of sclerotic nodules in the brain with mental defect and epilepsy which is known as tuberous sclerosis. $\mathrm{He}$ took an active part in the laicization of hospitals and in the foundation of training schools for nurses at La Salpêtrière, Lariboisière and Pitié hospitals. In 1905 he retired from the Bicêtre infirmary and was appointed director of the Vallée Foundation for the treatment of idiots and mentally defective children. He died on May 28, 1909.

\section{Luigi Bodio}

Lurgr BoDro, a celebrated Italian statistician, was born at Milan on October 12, 1840. After serving as lecturer in economics in the Technical Schools of Leghorn, Milan and Venice, he was appointed first permanent secretary of the Central Office of Statistics and in 1878 its director. In 1885 he was elected secretary to the International Institute of Statistics and in 1905 director. In 1901 he was made a senator of Italy. His writings were numerous and varied, the most important being on external commerce (1862), statistics in relation to politics, economics and allied sciences (1869), movement of population in Italy and other European States (1878) and Italian emigration (1894). He died on November 2. 1920.

\section{Amerindian Relics}

Some notable additions to the collections of the Smithsonian Institution illustrating the culture and history of the North American Indian peoples are recorded in communications recently issued by the Institution from Washington. The ethnographical interest of these objects is considerably enhanced by their historical and personal associations. Two corn husk dolls, for example, presented by the widow of the late J. N. B. Hewitt, who was the foremost authority of recent times on Iroquois culture and philosophy, are notable as being an exact reproduction of the dress of a man and woman of the Iroquois as described in contemporary accounts at the close of the eighteenth century. The Iroquois Federation of the Five Nations, founded in the seventeenth century, played a part of no little importance in the War of American Independence, though disrupted by a divided allegiance. The dresses of both male and female are of blue broadcloth decorated with glass, shell and porcelain beads and coloured ribbons. That of the woman is particularly elaborate.

Among Indian leaders in the war of resistance to the authority of the United States of the later nineteenth century, Sitting Bull, chief of the Sioux, won something of a world-wide reputation. Even in America, where at one time he was regarded as the worst of "bad Indians", he is now often made a 